\title{
Association between overexpression of Wip1 and prognosis of patients with non-small cell lung cancer
}

\author{
MIN ZHAO ${ }^{1,2}$, HONGBIN ZHANG $^{2}$, GUIYUN ZHU $^{3}$, JIAN LIANG $^{2}$, NING CHEN $^{3}$, \\ YONGHUI YANG ${ }^{3}$, XIANGCUN LIANG ${ }^{2}$, HONGMEI CAI ${ }^{2}$ and WEI LIU ${ }^{1,4}$ \\ ${ }^{1}$ Department of Oncology, Hebei Medical University, Shijiazhuang, Hebei 050011; \\ Departments of ${ }^{2}$ Lung Oncology and ${ }^{3}$ Pathology, Hebei Chest Hospital, \\ Research Center of Hebei Lung Cancer Prevention and Treatment, Shijiazhuang, Hebei 050041; \\ ${ }^{4}$ Department of Oncology, The Fourth Hospital of Hebei Medical University, Shijiazhuang, Hebei 050012, P.R. China
}

Received January 6, 2015; Accepted January 28, 2016

DOI: $10.3892 / \mathrm{ol} .2016 .4245$

\begin{abstract}
Wild-type p53-induced phosphatase 1 (Wip1), also termed PPM1D, is a member of the protein phosphatase $2 \mathrm{C}$ family, which is characterized by distinctive oncogenic properties. Overexpression of Wip1 is observed in certain types of human tumors that are associated with significantly poor prognosis. The present study aimed to detect the expression of Wip1 in non-small cell lung cancer (NSCLC) and to analyze its prognostic value in such patients. The protein expression level of Wip1 was compared between NSCLC and normal lung tissue specimens using by immunohistochemistry, and it was found that Wip1 was highly expressed in NSCLCs but was absent or weakly expressed in normal lung tissues. Detailed clinical and demographic information of patients were retrospectively collected pre- and postoperatively, and Kaplan-Meier survival and Cox's regression analyses were performed to evaluate the prognosis of patients. Survival analysis revealed that the overall survival rate for patients in the Wipl-positive expression group was significantly lower than that of the Wip1-negative group, and Cox multivariate analysis indicated that positive Wip1 expression, $\mathrm{pN}$ classification and pathological stage were significant prognostic predictors. The results of the current study suggest that Wip1 may be associated with pathological diagnosis and prognostic evaluation of NSCLC.
\end{abstract}

\section{Introduction}

Lung cancer is the leading cause of cancer-related mortality worldwide and can be categorized into two major histopathological groups: Non-small cell lung cancer (NSCLC) and small

Correspondence to: Professor Wei Liu, Department of Oncology, Hebei Medical University, 361 East Zhongshan Road, Shijiazhuang, Hebei 050011, P.R. China

E-mail: hebeiliuwei@hotmail.com

Key words: wild-type p53-induced phosphatase 1, lung cancer, non-small cell lung carcinoma, prognosis cell lung cancer (1). Approximately $80 \%$ of cases of human lung cancer are NSCLC, which itself can be subcategorized into adenocarcinoma, squamous cell carcinoma, adenosquamous carcinoma, large cell carcinoma and sarcomatoid carcinoma (2). Current treatments, including radiotherapy, chemotherapy and surgery, for NSCLC exhibit limited effectiveness and the prognosis remains poor, with an overall 5-year survival rate of only $15 \%$ (3). The poor outcome of lung cancer is primarily explained by the difficulty of early detection and anatomic localization of the tumors (4). Therefore, the identification of biomarkers that are expressed in NSCLC is important to elucidate the critical molecular events of these tumors, to accurately predict patient prognosis and to identify the most suitable pathways to target using novel therapeutic agents. A number of independent prognostic factors have been suggested for predicting survival and aiding in the management of patients with lung cancer (5).

Wild-type p53-induced phosphatase 1 (Wip1), also termed PPM1D, is a member of the protein phosphatase $2 \mathrm{C}$ family (6). It was originally identified in Burkitt's lymphoma cells during a screen for p53 target genes induced by ionizing radiation (7). Subsequently, Wip1 has been implicated as a negative regulator of p53 via its ability to attenuate p38 mitogen-activated protein kinase (MAPK) activity. Wipl dephosphorylates at least six proteins: Ataxia telangiectasia mutated, checkpoint kinase 1 (Chk1), Chk2, p53, p38 and Mdm2 (8). These proteins are DNA damage response markers and there expression is commonly decreased in DNA damage response pathways, which contribute to cancer progression $(8,9)$. Previous studies have demonstrated that Wipl is characterized by distinctive oncogenic properties and is overexpressed in a wide range of tumor tissues (10-14), including lung adenocarcinoma (15). However, previous studies have not investigated the expression of Wipl in different types of NSCLC or the association between Wip1 expression and overall survival (OS) of patients with NSCLC.

The present study aimed to detect the expression of Wip1 in NSCLC tissues and to analyze its prognostic value in patients with NSCLC. Wip1 protein expression was detected in 117 NSCLC and 15 normal lung tissue samples using immunohistochemistry. Detailed clinical and demographic information was retrospectively collected from the patients 
up to 5 years after surgery. Kaplan-Meier survival and Cox's regression analyses were performed to evaluate the prognosis of these patients.

\section{Materials and methods}

Tumor specimens. A total of 117 patients with NSCLC were admitted for surgical treatment at the Hebei Chest Hospital (Shijiazhuang, China) between January 2001 and December 2010. The cohort included 87 male and 30 female patients with a mean age of 56.9 years. Only the NSCLC patients with no metastasis and suitable for surgery were included in the present study. In addition, no patients received any treatment, including radiation or chemotherapy, prior to the surgery. Demographic and pathological tumor characteristics of the patients were collected prior to the initial surgery. Normal lung tissue samples $(n=15)$ were obtained from patients who undergone bronchiectasis surgery. These samples were dehydrated in an alcohol series (Sinopharm Chemical Reagent Co., Ltd., Beijing, China) (75\% for 1 h, $85 \%$ for $1 \mathrm{~h}, 95 \%$ for $4 \mathrm{~h}$ and $100 \%$ for $2 \mathrm{~h}$ ), cleaned in xylene (Sinopharm Chemical Reagent Co., Ltd.) and embedded in paraffin (Wanyao Chemical Technology Co., Ltd, Shijiazhuang, China) to prepare $5 \mu \mathrm{m}$ serial paraffin sections, and then stained by hematoxylin and eosin solution (Sigma-Aldrich, St. Louis, MO, USA) and confirmed as normal using light microscopy (DM IL LED; Leica Microsystems GmbH, Wetzlar, Germany). According to the World Health Organization classification system (16), tumor specimens were histopathologically diagnosed by two or more experienced pathologists as adenocarcinoma $(n=53)$, squamous cell carcinoma $(n=44)$, adenosquamous carcinoma $(n=9)$, large cell carcinoma $(n=6)$ and sarcomatoid carcinoma $(n=5)$. According to the TNM staging system (17), the specimens represented 25 pathological (p)-Stage I, 20 p-Stage II, 65 p-Stage III and $7 \mathrm{p}$-Stage IV tumors. The histological type and grade were confirmed by microscopic examination (DM IL LED; Leica Microsystems $\mathrm{GmbH}$ ) of hematoxylin and eosin-stained tissue slides (Sigma-Aldrich, St. Louis, MO, USA). All patients were consecutively enrolled in this study, and prognostic factors and disease progression were retrospectively collected. The study was approved by the Ethics Committee of Hebei Chest Hospital (Shijiazhuang, China) and informed consent was obtained from all recruited subjects.

Immunohistochemistry. The tissue sections were deparaffinized in xylene (Sinopharm Chemical Reagent Co., Ltd.), hydrated with $100 \%$ and $95 \%$ ethanol (Sinopharm Chemical Reagent Co., Ltd.), and then rinsed in distilled water. Endogenous peroxidase was blocked with $0.1 \% \mathrm{H}_{2} \mathrm{O}_{2}$ (Zhongshan Golden Bridge Biotechnology Co., Ltd., Beijing, China) for $20 \mathrm{~min}$. The sections were prepared by microwave antigen retrieval in $10 \mathrm{mM}$ citrate buffer ( $\mathrm{pH}$ 6.0; Zhongshan Golden Bridge Biotechnology Co., Ltd.) for $10 \mathrm{~min}$. The slides were subsequently incubated with serum blocking solution (Zhongshan Golden Bridge Biotechnology Co., Ltd.) for $1 \mathrm{~h}$ at $37^{\circ} \mathrm{C}$, rabbit anti-human polyclonal anti-Wip1 primary antibody (catalog no., SC-20712; 1:100 dilution; Santa Cruz Biotechnology, Inc., Dallas, TX, USA) overnight at $4^{\circ} \mathrm{C}$, goat anti-rabbit biotinylated secondary antibody (catalog no., ZB2010; dilution, 1:100; Zhongshan Golden Bridge Biotechnology Co., Ltd.) for $1 \mathrm{~h}$ at $37^{\circ} \mathrm{C}$ and streptavidin-horseradish peroxidase.
3,3'-Diaminobenzidine solution (Sigma-Aldrich) was used as a chromogen. The slides were then counterstained in a hematoxylin solution (Sigma-Aldrich) and visualized on the DM IL LED microscope (Leica Microsystems GmbH). Negative controls were performed by omitting the primary antibody incubation step.

Scoring of immunohistochemistry. Immunostaining of the tissues was graded semi-quantitatively considering the staining intensity results determined by two pathologists that were blinded to the clinicopathological variables. The staining intensity was scored using the following scale of four grades: 0 , no staining; 1, weak staining; 2, moderate staining; and 3, strong staining of cancer cells. Wip1 expression in the cancer tissue was defined as positive when the staining intensity score was 2 or 3 .

Statistical analysis. Statistical analysis was performed using SPSS version 16.0 statistical software (SPSS Inc., Chicago, IL, USA). Data were presented as the mean \pm standard deviation. The associations between Wip1 expression and categorical variables were analyzed by Pearson's $\chi^{2}$ test; excluding age, which was analyzed by Student's t-test. The survival curves were estimated using the Kaplan-Meier method and the statistical significance between survival curves was assessed using the log-rank test. OS was determined from the date of surgery to the date of mortality. Significant variables from the univariate analysis were entered into the Cox proportional hazard model. $\mathrm{P}<0.05$ indicated a statistically significant difference and all tests were two-sided.

\section{Results}

Wipl expression in NSCLC by immunohistochemistry. Immunohistochemistry was used to analyze the expression of Wip1 protein in the NSCLC tissues. In the normal lung tissues, the expression of Wip1 was not detected or was weakly expressed (Fig. 1A). However, cytoplasmic staining was observed in the human NSCLC tissue samples (Fig. 1B-D). Scoring of the immunohistochemical slides revealed positive Wip1 expression (immunostaining score, 2/3) in 69.3\% (81/117) of NSCLC samples. Weak Wip1 expression (immunostaining score, 0/1) was observed in $30.7 \%$ (36/117) of NSCLC samples (Table I).

Association between Wipl expression, and demographic and pathological factors of NSCLC. Statistical analysis using the $\chi^{2}$ test identified that of the status of Wip1 expression was correlated with demographic and pathological factors of the tumors (Table II). Notably, Wip1 overexpression was predominantly observed in lung adenocarcinoma compared with other histological subtypes of NSCLC $(\mathrm{P}<0.01$; Table II); in p-Stage III-IV compared with p-Stage I-II $(\mathrm{P}=0.045)$; and in pT2-4 tumors compared with pT1 tumors $(\mathrm{P}=0.004)$. However, no statistically significant correlation was identified between Wip1 expression and the other demographic and pathological factors of NSCLC analyzed, such as age, gender, histological differentiation or $\mathrm{pN}$ classification (Table II).

Overexpression of Wipl correlates with the poor prognosis of NSCLC. The OS of Wip1-negative and Wip1-positive groups 
Table I. Association between Wip1 immunostaining scores and NSCLC histological subtype.

\begin{tabular}{|c|c|c|c|c|c|}
\hline \multirow[b]{2}{*}{ NSCLC subtype } & \multicolumn{5}{|c|}{ Wip1 immunostaining score, n (\%) } \\
\hline & 0 & 1 & 2 & 3 & Total \\
\hline Adenocarcinoma & $3(5.7)$ & $3(5.6)$ & $44(83.0)$ & $3(5.7)$ & $53(88.7)$ \\
\hline Squamous cell carcinoma & $5(11.4)$ & $14(31.8)$ & $23(52.3)$ & $2(4.5)$ & $44(37.6)$ \\
\hline Others $^{\mathrm{a}}$ & $4(2.0)$ & $9(45.0)$ & $6(30.0)$ & $1(5.0)$ & $20(17.2)$ \\
\hline Total & $12(10.2)$ & $24(20.5)$ & $75(64.1)$ & $6(5.2)$ & $117(100)$ \\
\hline
\end{tabular}

${ }^{a}$ Other subtypes included 9 adenosquamous carcinoma, 6 large cell carcinoma and 5 sarcomatoid carcinoma cases. Wip1, wild-type p53-induced phosphatase 1; NSCLC, non-small cell lung carcinoma. The expression of Wip1 in control tissues was 0 (no staining; not shown).
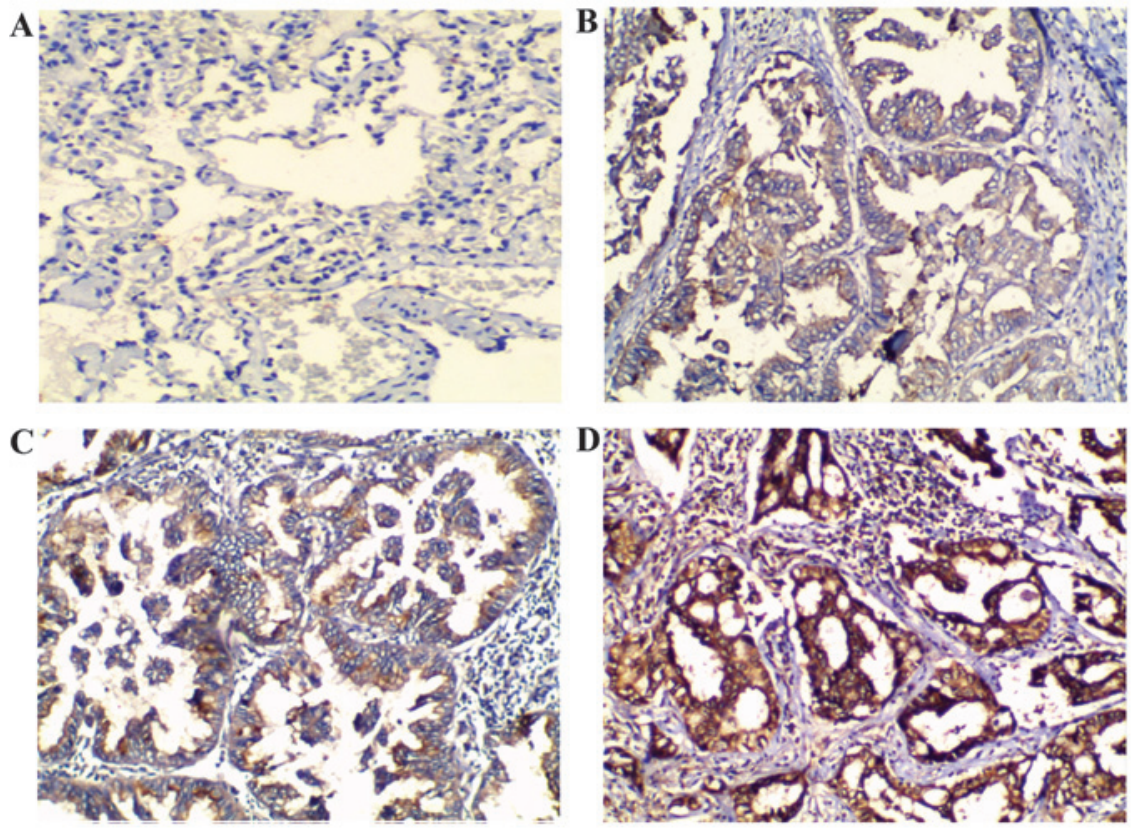

Figure 1. Wild-type p53-induced phosphatase 1 (Wip1) expression in normal lung and non small cell lung cancer (NSCLC) tissues using immunohistochemistry. (A) No Wip1 expression in normal lung tissue. (B) Weak (+1), (C) moderate (+2) and (D) strong (+3) Wip1 expression in NSCLC tissues. 3,3'-Diaminobenzidine and hematoxylin staining; magnification, x100.

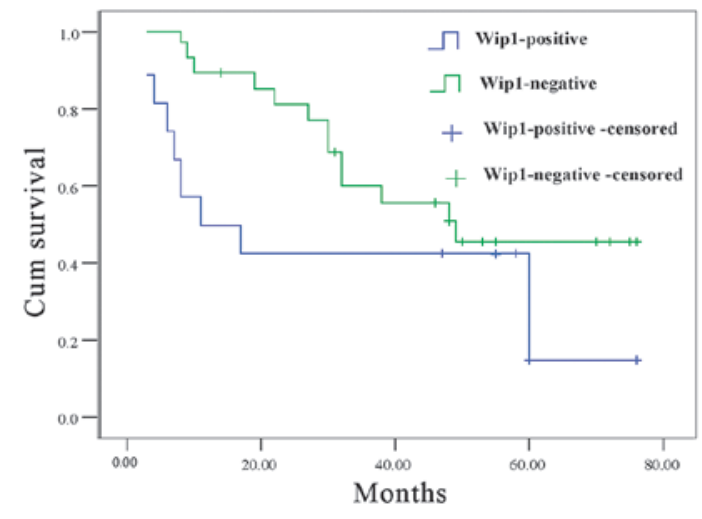

Figure 2. Kaplan-Meier survival curves for Wip1 expression. Patients with positive Wip1 expression displayed a significantly worse outcome compared with negative Wip1 expression patients ( $\mathrm{P}=0.014, \log$-rank test). Cum, cumulative; Wip1, wild-type p53-induced phosphatase 1; censored, where the patients' survival time is unknown. The survival time is known to be longer than the observed censored time, as the survival includes discontinued follow-up and mortality by other causes. The number of Wip-positive censored patients is 10 and Wip-negative censored patients is 4 . were examined. A statistically significant difference between the two groups was observed using the log-rank test. The survival of Wipl-negative patients was significantly longer than that observed for the Wip1-positive patients (45.6 and $18.5 \%$ 5-year survival rate, respectively; $\mathrm{P}=0.014$; Fig. 2).

Multivariate analysis (Cox proportional hazard model) for age, gender, histological differentiation, TNM stage and overexpression of Wip1 was performed to examine the association between possible prognostic factors and survival (Table III). It was identified that the $\mathrm{pN}$ classification $(\mathrm{P}=0.022)$, $\mathrm{p}$-Stage $(\mathrm{P}=0.013)$ and Wip1 overexpression $(\mathrm{P}=0.009)$ were statistically significant predictors for OS (Table III).

\section{Discussion}

The present study determined that: i) Wip1 is highly expressed in NSCLCs; ii) the OS rate for patients in the Wip1-positive expression group was significantly lower than that of the Wip1-negative group, as determined by survival analysis; and 
Table II. Association between Wip1 expression, and demographic and pathological tumor characteristics of patients with NSCLC.

\begin{tabular}{|c|c|c|c|}
\hline \multirow[b]{2}{*}{ Clinical parameter } & \multicolumn{2}{|c|}{ Wip1 protein status, $\mathrm{n}^{\mathrm{a}}$} & \multirow[b]{2}{*}{ P-value ${ }^{b}$} \\
\hline & + & - & \\
\hline Age, years & $57.8 \pm 11.5^{\mathrm{c}}$ & $56.1 \pm 9.1^{\mathrm{c}}$ & 0.268 \\
\hline Gender & & & 0.138 \\
\hline Male & 57 & 30 & \\
\hline Female & 24 & 6 & \\
\hline Histology & & & $<0.001$ \\
\hline Adenocarcinoma & 49 & 4 & \\
\hline Squamous cell carcinoma & 25 & 19 & \\
\hline Others & 7 & 13 & \\
\hline Differentiation & & & 0.249 \\
\hline Well & 24 & 7 & \\
\hline Moderate/poor & 57 & 29 & \\
\hline pT classification & & & 0.004 \\
\hline $\mathrm{T} 1$ & 12 & 14 & \\
\hline $\mathrm{T} 2-4$ & 69 & 22 & \\
\hline $\mathrm{pN}$ classification & & & 0.157 \\
\hline N0 & 45 & 25 & \\
\hline $\mathrm{N} 1-3$ & 36 & 11 & \\
\hline p-Stage & & & 0.045 \\
\hline I-II & 55 & 11 & \\
\hline III-IV & 26 & 15 & \\
\hline
\end{tabular}

${ }^{a}$ Wip1(+) group ( $\mathrm{n}=81$ ) is defined as cases with moderate and strong expression (immunostaining score, 2/3); Wip1(-) group (n=36) is defined as cases with weak expression (immunostaining score, $0 / 1$ ). Data were presented as mean \pm standard deviation. ${ }^{\mathrm{b}}$ Pearson $\chi^{2}$ test was used to derive P-values, excluding age, which was analyzed by Student's t-test. 'Data are presented as mean \pm range. Wip1, wild-type p53-induced phosphatase 1; NSCLC, non-small cell lung carcinoma.

Table III. Cox proportional hazard model analysis of survival time.

$95 \%$ CI for $\operatorname{Exp}(\mathrm{B})$

\begin{tabular}{|c|c|c|c|c|c|}
\hline & Wald & $\operatorname{Exp}(\mathrm{B})$ & Lower & Upper & P-value \\
\hline Wip1 (+ vs. - $)^{\mathrm{a}}$ & 6.815 & 5.096 & 1.501 & 17.303 & 0.009 \\
\hline p-Stage (I-II vs. III-IV) & 6.150 & 0.159 & 0.037 & 0.680 & 0.013 \\
\hline pT classification (T1 vs. T2-4) & 1.502 & 4.712 & 0.395 & 26.210 & 0.220 \\
\hline pN classification (N0 vs. N1-3) & 5.218 & 5.488 & 1.273 & 23.647 & 0.022 \\
\hline Histology (adenocarcinoma vs. non-adenocarcinoma ${ }^{b}$ ) & 0.006 & 1.564 & 0.561 & 9.377 & 0.937 \\
\hline Differentiation (well vs. moderate/poor) & 1.688 & 0.306 & 0.051 & 1.825 & 0.194 \\
\hline Gender (male vs. female) & 1.185 & 4.439 & 0.303 & 5.005 & 0.276 \\
\hline Age & 0.143 & 0.991 & 0.948 & 1.037 & 0.705 \\
\hline
\end{tabular}

${ }^{a} \mathrm{Wip} 1(+)$ is defined as cases with moderate and strong expression (immunostaining score, 2/3); Wip1(-) is defined as cases with weak expres-

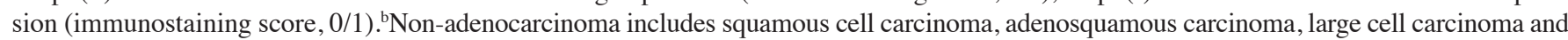
sarcomatoid carcinoma. CI, confidence interval; Wip1, wild-type p53-induced phosphatase 1.

iii) positive Wip1 expression, $\mathrm{pN}$ classification and $\mathrm{p}$-Stage are significant prognostic predictors of NSCLC, as determined by Cox multivariate analysis.
Human Wipl protein has a molecular weight of $\sim 61 \mathrm{kD}$ and is composed of 605 amino acids (6). Wipl has been identified in colon cells expressing a mutant form of $\mathrm{p} 53$, and mediates a 
negative feedback regulation on $\mathrm{p} 53$ through the $\mathrm{p} 38 \mathrm{MAPK} / \mathrm{p} 53$ signaling pathway, leading to decreased expression of p53 and p53 mutants, suggesting a close association between Wip1 and p53 (18). A number of previous reports also identified Wip1 overexpression in mouse embryonic fibroblasts and in accelerated cancer progression (19-21). To the best of our knowledge, the present study is the first to quantify Wipl expression in different types of lung cancer and normal lung tissue using immunohistochemistry. It was observed that Wip1 protein levels were significantly higher in lung cancer tissue compared with normal tissue, and Wip1 overexpression was observed predominantly in lung adenocarcinoma. The current results are consistent with a previous finding that Wip1 mRNA expression is significantly higher in the early stages of NSCLC (22) and with the observation of increased Wipl expression in lung adenocarcinoma (15). Using univariate analysis, Zhao et al identified that Wip1 mRNA levels were correlated with the p-Stage of NSCLC (22). The present study also revealed that Wip1 protein levels were correlated with p-Stage and pT classification: Overexpression was predominantly observed in p-Stage III-IV (versus p-Stage I-II) and pT2-4 tumors (versus pT1 tumors). However, no statistically significant correlations were found in NSCLCs between Wip1 expression, and other demographic and pathological factors, such as age, gender, histological differentiation and $\mathrm{pN}$ classification.

An underlying hypothesis of the modern era of cancer research has been that prediction of a patient's prognosis or response to therapy may be improved by combining standard clinical variables (i.e., tumor size, differentiation or stage) with intrinsic genetic or biochemical characteristics of the tumors (23). Overexpression of Wip1 in lung adenocarcinoma, pancreatic neuroendocrine tumors, endometrial cancer and gliomas is has previously been identified as a prognostic indicator for certain patients at a high risk of tumor-related mortality $(13,15,24,25)$. Over the past several decades, hundreds of papers have proposed a variety of molecular markers or proteins that may have prognostic significance in NSCLC; for example, p53 (26). Satoh et al reported that there was a statistically significant association between increased Wip1 expression and lower OS rate (15). In the current study, survival analysis identified that the OS rate for patients with NSCLC in the Wip1-positive expression group was significantly lower than that of the Wip1-negative group. Furthermore, Cox multivariate analysis revealed that positive Wip1 expression, as well as the two clinical variables $\mathrm{pN}$ classification and $\mathrm{p}$-Stage, were significant prognostic predictors of NSCLC.

In conclusion, the present study demonstrated that Wip1 is overexpressed in NSCLC and that Wip1 overexpression is significantly associated with poorer OS in NSCLC. Therefore, Wip1 status appears to be an independent molecular marker associated with worse clinical outcomes and prognosis of NSCLC. However, the mechanism responsible for the role of Wip1 in tumorigenesis and its biological function merits further evaluation.

\section{Acknowledgements}

The present study was supported by grants from the Natural Science Foundation of Hebei Province (no. H2013315011).

\section{References}

1. Spira A and Ettinger DS: Multidisciplinary management of lung cancer. N Engl J Med 350: 379-392, 2004.

2. Govindan R, Page N, Morgensztern D, Read W, Tierney R, Vlahiotis A, Spitznagel EL and Piccirillo J: Changing epidemiology of small-cell lung cancer in the United States over the last 30 years: Analysis of the surveillance, epidemiologic, and end results database. J Clin Oncol 24: 4539-4544, 2006.

3. Jemal A, Siegel R, Ward E, Murray T, Xu J, Smigal C and Thun MJ: Cancer statistics, 2006. CA Cancer J Clin 56: 106-130, 2006.

4. Sun S, Schiller JH, Spinola M and Minna JD: New molecularly targeted therapies for lung cancer. J Clin Invest 117: 2740-2750, 2007.

5. Ciancio N, Galasso MG, Campisi R, Bivona L, Migliore M and Di Maria GU: Prognostic value of p53 and Ki67 expression in fiberoptic bronchial biopsies of patients with non small cell lung cancer. Multidiscip Respir Med 7: 29, 2012.

6. Moorhead GB, Trinkle-Mulcahy L and Ulke-Lemée A: Emerging roles of nuclear protein phosphatases. Nat Rev Mol Cell Biol 8: 234-244, 2007.

7. Fiscella K, Franks P and Shields CG: Perceived family criticism and primary care utilization: Psychosocial and biomedical pathways. Fam Process 36: 25-41, 1997.

8. Lu X, Nguyen TA, Moon SH, Darlington Y, Sommer M and Donehower LA: The type $2 \mathrm{C}$ phosphatase Wip1: An oncogenic regulator of tumor suppressor and DNA damage response pathways. Cancer Metastasis Rev 27: 123-135, 2008.

9. Gorgoulis VG, Vassiliou LV, Karakaidos P, Zacharatos P, Kotsinas A, Liloglou T, Venere M, Ditullio RA Jr, Kastrinakis NG, Levy B, et al: Activation of the DNA damage checkpoint and genomic instability in human precancerous lesions. Nature 434: 907-913, 2005.

10. Castellino RC, De Bortoli M, Lu X, Moon SH, Nguyen TA, Shepard MA, Rao PH, Donehower LA and Kim JY: Medulloblastomas overexpress the p53-inactivating oncogene WIP1/PPM1D. J Neurooncol 86: 245-256, 2008.

11. Saito-Ohara F, Imoto I, Inoue J, Hosoi H, Nakagawara A, Sugimoto T and Inazawa J: PPM1D is a potential target for $17 \mathrm{q}$ gain in neuroblastoma. Cancer Res 63: 1876-1883, 2003.

12. Hirasawa A, Saito-Ohara F, Inoue J, Aoki D, Susumu N, Yokoyama T, Nozawa S, Inazawa J and Imoto I: Association of 17q21-q24 gain in ovarian clear cell adenocarcinomas with poor prognosis and identification of PPM1D and APPBP2 as likely amplification targets. Clin Cancer Res 9: 1995-2004, 2003.

13. Hu W, Feng Z, Modica I, Klimstra DS, Song L, Allen PJ, Brennan MF, Levine AJ and Tang LH: Gene amplifications in well-differentiated pancreatic neuroendocrine tumors inactivate the p53 pathway. Genes Cancer 1: 360-368, 2010.

14. Li J, Yang Y, Peng Y, Austin RJ, van Eyndhoven WG, Nguyen KC, Gabriele T, McCurrach ME, Marks JR, Hoey T, et al: Oncogenic properties of PPM1D located within a breast cancer amplification epicenter at 17q23. Nat Genet 31: 133-134, 2002.

15. Satoh N, Maniwa Y, Bermudez VP, Nishimura K, Nishio W, Yoshimura M, Okita Y, Ohbayashi C, Hurwitz J and Hayashi Y: Oncogenic phosphatase Wipl is a novel prognostic marker for lung adenocarcinoma patient survival. Cancer Sci 102: 1101-1106, 2011.

16. Travis WD, Brambilla E, Müller-Hermelink HK and Harris CC (eds): Tumours of the lung. In: World Health Organization Classification of Tumours. Pathology and Genetics of Tumours of the Lung, Pleura, Thymus and Heart. IARC Press, Lyon, p10, 2004.

17. Goldstraw P, Crowley J, Chansky K, Giroux DJ, Groome PA, Rami-Porta R, Postmus PE, Rusch V and Sobin L; International Association for the Study of Lung Cancer International Staging Committee; Participating Institutions: The IASLC Lung Cancer Staging Project: proposals for the revision of the TNM stage groupings in the forthcoming (seventh) edition of the TNM Classification of malignant tumours. J Thorac Oncol 2: 706-714, 2007.

18. Park JY, Song JY, Kim HM, Han HS, Seol HS, Jang SJ and Choi J: p53-Independent expression of wild-type p53-induced phosphatase 1 (Wip1) in methylmethane sulfonate-treated cancer cell lines and human tumors. Int J Biochem Cell Biol 44: 896-904, 2012.

19. Bulavin DV, Demidov ON, Saito S, Kauraniemi P, Phillips C, Amundson SA, Ambrosino C, Sauter G, Nebreda AR, Anderson CW, et al: Amplification of PPM1D in human tumors abrogates p53 tumor-suppressor activity. Nat Genet 31: 210-215, 2002 . 
20. Nannenga B, Lu X, Dumble M, Van Maanen M, Nguyen TA, Sutton R, Kumar TR and Donehower LA: Augmented cancer resistance and DNA damage response phenotypes in PPM1D null mice. Mol Carcinog 45: 594-604, 2006.

21. Demidov ON, Kek C, Shreeram S, Timofeev O, Fornace AJ, Appella E and Bulavin DV: The role of the MKK6/p38 MAPK pathway in Wip1-dependent regulation of ErbB2-driven mammary gland tumorigenesis. Oncogene 26: 2502-2506, 2007.

22. Zhao JX ZW, Sun L, Luo H H and Gu Y: Expression of Wipl in non small cell lung cancer tissue and cells. Chin J Pathophysiol 25: 1731-1735, 2009 (In Chinese).

23. Singhal S, Vachani A, Antin-Ozerkis D, Kaiser LR and Albelda SM: Prognostic implications of cell cycle, apoptosis, and angiogenesis biomarkers in non-small cell lung cancer: A review. Clin Cancer Res 11: 3974-3986, 2005.
24. Hirasawa A, Aoki D, Inoue J, Imoto I, Susumu N, Sugano K, Nozawa $S$ and Inazawa J: Unfavorable prognostic factors associated with high frequency of microsatellite instability and comparative genomic hybridization analysis in endometrial cancer. Clin Cancer Res 9: 5675-5682, 2003.

25. Liang C, Guo E, Lu S, Wang S, Kang C, Chang L, Liu L, Zhang G, Wu Z, Zhao Z, et al: Over-expression of wild-type p53-induced phosphatase 1 confers poor prognosis of patients with gliomas. Brain Res 1444: 65-75, 2012.

26. Campling BG and El-Deiry WS: Clinical implication of p53 mutation in lung cancer. Mol Biotechnol 24: 141-156, 2003. 